\title{
ASSESSMENT OF PHYTOCHEMICAL CONSTITUENTS, IN VITRO ANTIMICROBIAL AND ANTIOXIDANT POTENTIAL OF ULVA EXTRACTS FROM VISHAKHAPATNAM COAST
}

\author{
PRINCELY S*, DHANARAJU MD \\ Department of Pharmaceutical Biotechnology, Research Laboratory, GIET School of Pharmacy, Rajahmundry - 533 296, Andhra Pradesh, \\ India. Email: sprincelympharm@gmail.com
}

Received: 20 March 2017, Revised and Accepted: 24 April 2017

\section{ABSTRACT}

Objective: Antimicrobial drug resistance is the foremost problem faced worldwide with the current antibiotic therapy in treating infectious diseases. Marine algae were considered as a potential source of biologically active compounds with antibacterial, antifungal, antiviral, and anticancer activities.

Materials and Methods: In the present investigation, the purified fractions of marine algal crude extracts of different solvents such as aqueous, ethyl acetate (EtAc), and ethanol for antioxidant (1,1-diphenyl-2-picrylhydrazyl radical scavenging assay) and antimicrobial activities (agar well diffusion assay) were evaluated.

Results: The extracts of EtAc, ethanol, and water showed minimum inhibitory concentration values of 3.125, 6.25, and 12.25 $\mu \mathrm{g} / \mathrm{ml}$, respectively, for tested bacterial pathogens. The active fractions showed very little activity against Klebsiella pneumonia and Salmonella Typhi, and no activity was observed against Pseudomonas aeruginosa. The results of our screening showed that the EtAc marine algal fractions were active against some Grampositive, Gram-negative bacteria and Candida albicans. The phytochemical analysis of aqueous, ethanolic, and EtAc extracts of marine algae showed the presence of the various phytochemical constituents such as carbohydrates, phenols, and amino acids. The ethanolic extracts showed the highest antioxidant activity as compared to aqueous and EtAc extracts.

Conclusion: This work can be extended further to isolate, characterize, and discover more bioactive metabolites from marine algae, which can be exploited for the production of lead molecules in pharmaceuticals for the treatment of chronic diseases.

Keywords: Marine algae, Phytochemicals, Antimicrobial, Antioxidant, 1,1-diphenyl-2-picrylhydrazyl.

(C) 2017 The Authors. Published by Innovare Academic Sciences Pvt Ltd. This is an open access article under the CC BY license (http://creativecommons. org/licenses/by/4. 0/) DOI: http://dx.doi.org/10.22159/ajpcr.2017.v10i8.18582

\section{INTRODUCTION}

The term natural products commonly refer to herbs, herbal concoctions, dietary supplements, or alternative medicine. However, in general, natural products are chemical compounds or substances produced by living microbes, plants, or animal sources. Like chemicals, natural products includes various classes of compounds such as terpenoids, polyketides, amino acids, peptides, proteins, carbohydrates, lipids, nucleic acid bases, ribonucleic acid, and deoxyribonucleic acid among many others. It usually possesses pharmacological or biological activity suitable for use in pharmaceutical drug discovery and drug design $[1,2]$.

The medicinal value of plant and animal extracts can be extensively correlated with the history of humankind. Focusing on bioproducts, recent trends in drug research from natural sources suggested that macroalgae are an attractive source of potential drug compounds in several biochemical and pharmacological investigations. Seaweeds (marine algae) belong to a group of eukaryotic known as algae. Seaweeds are classified as rhodophyta (red algae), phaeophyta (brown algae), or chlorophyta (green algae) depending on their nutrient, pigments and chemical composition. Like other plants, seaweeds contain various inorganic and organic substances which can benefit human health and considered as a source of secondary metabolites characterized by a broad spectrum of biological activities. Specific studies carried out in the Atlantic, Pacific, and Indian oceans on seaweeds have demonstrated antibacterial, antifungal, and antiviral activities (e.g., Burkholder et al. 1960, Hornsey and Hide, 1974; Naqvi et al., 1990; Rinehart et al., 1981; Reichelt and Borowitzka, 1983; Hodgson, 1984), as well as ichthyotoxicity (e.g., Paul and Fenical 1986), cytotoxicity (e.g., Paul and Fenical 1991) and antimitotic properties (e.g., Munro et al., 1991). According to their chemical structure, most isolated compounds belong to sulfated polysaccharides, phenolics, terpenoids, lactons, sterol, and fatty acids (McDermid and Stuercke, 2003; Qi et al., 2005; Duan et al., 2006).

Seaweeds or marine macroalgae are the renewable living resources which are also used as food and fertilizer in many parts of the world. Seaweeds are of nutritional interest as low-calorie food but rich in vitamins, minerals, proteins, polysaccharides and dietary fibers [3,4]. The lipids are present in very small amounts which are unsaturated and afford protection against cardiovascular pathogens. Its antioxidant activity is one of the most important bioactivities and lots of algal and algae-derived compounds such as carotenoids, phenolics, terpenoids, and sulfated polysaccharides exhibit potent antioxidant activities. The antioxidant activities of these compounds are mainly attributed to scavenging activity against superoxide and hydroxyl radicals, chelating ability, quenching singlet and triplet oxygen and reducing power $[4,5]$. Furthermore, many polysaccharides found in seaweeds have diverse biological activities, including effects on the immune system and cancer. Recent reports indicated that there is an inverse relationship between the dietary intake of antioxidant-rich foods and the incidence of human diseases.

The increase in antibiotic-resistant microorganisms is a serious issue because of the constant concern of reduced efficiency of antibiotics in the treatment of human diseases necessitated the development of new antimicrobial compounds [6]. Macroalgae are one of the best sources of bioactive compounds as they produce varieties of secondary metabolites with broad spectrum of antimicrobial agents such as chlorellin derivatives and halogenated compounds such as polysaccharides, peptides, proteins, vitamins, haloforms, halogenated alkanes and alkenes, alcohols, aldehydes, hydroquinones, sterols, ketones, and cyclic polysulfides [7,8]. Many of these could be developed into antiseptics and cleansing agents, but their antibiotic activity 
in vivo is often only achieved at toxic concentrations. A study on the 17 macroalgae collected from southern India coast indicated that about 94\% exhibited antibiotic activity toward Shrimp and fish pathogens [9].

The genus Ulva popularly known as sea lettuce is one of the most common and abundant green macroalgae worldwide (Lahaye and Robic, 2007). Despite its wide distribution, it is poorly utilized (Ray and Lahaye, 1995) and only a small part of its biomass is used as food or animal feed due to its nutritional components (vitamins, oligo elements, minerals, and dietary fibers) (Pengzhan et al., 2003); organic crop fertilizer (Mulbry et al., 2005), effluent biofilter (Msuya and Neori, 2002) and more recently, as plant protectant (Cluzet et al., 2004).

Although literature speaks diverse studies of bioactivity to marine flora against several pathogens our work on testing the antibacterial efficacies of macroalgae Ulva species depend mainly on human multidrug-resistant pathogen. In this study, we continued the investigation of antimicrobial and antioxidant activities of green algae (Ulva species) that were collected from the intertidal rocky surfaces of Vishakhapatnam coast. The aim of the present work was to prepare different solvent extracts of Ulva species, separate fractions by column chromatography, detect active fractions by thin layer chromatography (TLC), screen their purified fractions against pathogenic bacterial and fungal strains, to detect antioxidant activity by 1,1-diphenyl-2-picrylhydrazyl (DPPH) assay and to determine the functional groups of the active fractions by Fourier transform infrared (FTIR) spectroscopy. The overall goal of this study was to increase the knowledge of the chemically-mediated bioactivity in the marine flora by examining its most representative macrophytes and screening for biological activities (Fig. 1).

\section{MATERIALS AND METHODS}

\section{Materials}

Ethyl acetate (EtAc), ethanol, dimethyl sulfoxide (DMSO), and silica gel were purchased from Virat Lab, Hyderabad. Chemicals such as DPPH and ascorbic acid were procured from Molychem Pvt. Ltd. (Mumbai, India). Folin-Ciocalteu reagent, Ninhydrin reagent, and Dragendroff's reagent were purchased from SD Fine Chemicals Limited, Mumbai. Chloroform, butanol, glacial acetic acid, and other acids were procured from Sigma Chemicals. All other chemicals unless and otherwise mentioned were obtained from Hi-Media Laboratories and Molychem Pvt. Ltd. (Mumbai, India). Green algae (identified as Ulva species) were collected from rocky intertidal surfaces of Vishakhapatnam Coast and identified by Krishnamurthy Institute of Algology, Chennai. All other chemicals and reagents were of the highest quality available and obtained commercially.

\section{Spectrophotometric measurements}

Spectrophotometric measurements were performed by ultravioletvisible Double beam spectrophotometer (ELICO SL-210).

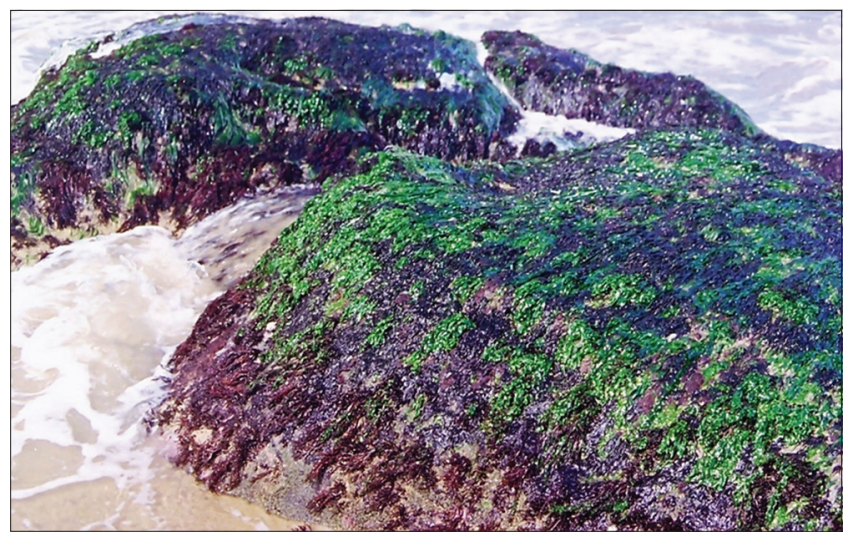

Fig. 1: Marine algae sample collected from rocky intertidal surfaces

\section{Methodology}

Collection of sample

Live and healthy macroalgal samples were collected from the intertidal rocky surfaces of Vishakhapatnam coast in the month of February (2016) and brought to laboratory. The collected algae were rinsed with water to remove epiphytes and necrotic parts and thoroughly rinsed with sterile water to remove any associated debris. The marine algae after rinsing were dried carefully in the shade under room temperature for 10 days and immediately subjected to extraction.

\section{Identification of macroalgae}

The macroalgal isolates were identified using the morphological variation studies and taxonomic publications of algae [12-15]. Semipermanent slides were prepared and preserved in algal herbarium. The algal morphotypes such as filamentous nature, size, shape of vegetative cells, and akinetes were identified. The identification of the investigated marine algae was verified by Krishnamurthy Institute of Algology, Chennai.

\section{Extraction}

\section{Preparation of macroalgal extracts}

Dried marine algae were weighed and chopped and then finely grounded by Ulta-Turrax T25 dispersing instrument. $10 \mathrm{~g}$ of the dried biomass was extracted with $100 \mathrm{ml}$ of distilled water and various organic solvents ethanol and EtAc for one week at room temperature for complete extraction of the bioactive components. The supernatants were collected after centrifugation at $10,000 \mathrm{rpm}$ for 10 minutes. The resulting pellet was re-extracted for two to three times and the supernatant was transferred to a clean $2 \mathrm{~mL}$ Eppendorf tube. The extracts were evaporated to dryness under reduced pressure using rotary vacuum evaporator below $45^{\circ} \mathrm{C}$ (Perez et al. 1990). Dried residues were re-dissolved in dimethylsulfoxide (DMSO) and stored in sterile test tubes at $4{ }^{\circ} \mathrm{C}$ until further screening [16].

\section{Preliminary phytochemical screening}

Phytochemical screening was performed using standard procedures (Trease and Evans, 1983; Harbourne, 1973). The aqueous, ethanolic, and EtAc extracts were evaluated for the presence of phytoconstituents such as alkaloids, carbohydrates, proteins, phenol, anthraquinones, coumarins, flavonoids, saponins, tannins, terpenes, reducing sugars, and glycosides using standard qualitative methods [17,18].

\section{Estimation of nutritional value of algal species $[19,20]$}

\section{Protein estimation}

The dry seaweeds material was extracted using Tris HCL buffer $(0.1 \mathrm{M}$ $\mathrm{pH} 7.5$ ) overnight at $4^{\circ} \mathrm{C}$ with stirring. After centrifugation, the total protein in the supernatant was estimated spectrophotometrically at $750 \mathrm{~nm}$ (Lowry et al., 1951) using bovine serum albumin as a standard. Proteins were expressed as percentage of algal dry weight.

\section{Carbohydrates estimation}

The total carbohydrates were estimated by following the phenolsulfuric acid method of Dubois et al. (1956), after extraction with $2.5 \mathrm{~N}$ $\mathrm{HCL}$ for $3 \mathrm{hrs}$ at $100^{\circ} \mathrm{C}$. The content was calculated in percentage by referring to glucose standard curve.

\section{Lipid estimation}

Lipids were extracted with a chloroform-methanol method (Bligh and Dyer, 1959) and expressed in percentage. The lipids in chloroform were dried over anhydrous sodium sulfate, after which the solvent was removed by heating at $80^{\circ} \mathrm{C}$ under vacuum.

\section{Ash estimation}

Ash content was acquired by heating the sample overnight in a furnace at $525^{\circ} \mathrm{C}$, and the content was determined gravimetrically. 


\section{Moisture estimation}

The moisture content was determined by oven method at $105^{\circ} \mathrm{C}$ until their constant weight was obtained.

\section{TLC}

The stationary phase (silica gel) was prepared as slurry with water at 1:2 ratio and was applied to the glass plate or an inert plastic sheet using TLC applicator of $0.25 \mathrm{mM}$ thickness for analytical separation and $2.5 \mathrm{mM}$ thickness for preparation. Calcium sulfate $\left(\mathrm{CaSO}_{4}\right), 1 / 2 \mathrm{H}_{2} \mathrm{O}$ (gypsum) $(10.15 \%)$ is incorporated to the adsorbent as a binder since it facilitates the adhesion of the adsorbent to the plate. After the application of the adsorbent, the plates are air dried for 15 minutes. This process is also known as activation of the adsorbent. The plates can be used immediately or stored in desiccators $[21,22]$.

\section{Compounds detection}

Several methods were available to detect the separated compounds. Different types of spraying reagents are used to detect the different components.

Phenols

The presence of phenols in the developed chromatograms was detected by spraying Folin-Ciocalteu reagent. After the plates were heated at $80^{\circ} \mathrm{C}$ for 10 minutes, there was a positive reaction to the formation of blue color spot.

Amino acids

The presence of amino acids in the developed chromatograms was detected by spraying the $0.1 \%$ ninhydrin reagent. After the plates were heated at $80^{\circ} \mathrm{C}$ for 10 minutes, there was a positive reaction to formation of pink (or) purple spots.

Sterols

The presence of sterols in the developed chromatogram was detected by spraying Folin-Ciocalteu reagent. After the plates were heated at $80^{\circ} \mathrm{C}$ for 10 minutes, a positive reaction to formation of blue color spot was seen.

\section{Saponins}

The presence of saponins in the developed chromatogram was detected using iodine vapors, and possible reaction to formation of yellow color spot was seen.

\section{Determination of $R_{f}$ value}

The $\mathrm{R}_{\mathrm{f}}$ values of the various bioactive compounds were calculated using the following formula.

$$
\mathrm{R}_{\mathrm{f}}=\frac{\text { Distance travelled by the solute }}{\text { Distance travelled by the solvent }}
$$

\section{Purification of crude extracts}

The crude extracts (ethanol, EtAc and water) of seaweeds were purified using silica gel column chromatography. The column was packed with $10 \mathrm{~g}$ of silica gel (60-120 mesh size) using hexane solvent with the maximum height of $20 \mathrm{~cm}$. Each crude extract was weighed $(1.5 \mathrm{~g}$ of ethanol, $1.6 \mathrm{~g}$ of EtAc and $1.5 \mathrm{~g}$ of water) and eluted successively with $25 \mathrm{ml}$ of respective solvents and the same were loaded on top of the silica gel separately. The corresponding fractions (1-5) were obtained and each fraction ( $5 \mathrm{ml}$ volume) was eluted for 5-10 minutes. All the fractions were concentrated by rotary vacuum evaporator below $45^{\circ} \mathrm{C}$ and stored in sterile test tubes at $4^{\circ} \mathrm{C}$ for further use [23-25].

\section{Minimum inhibitory concentrations (MICs)}

Microdilution assay

The marine algal extracts that showed antimicrobial activity by agar well diffusion method were subjected to MIC assay. The macroalgal extracts were diluted to obtain concentration ranging from 100, $50,25,12.5,6.25,0.625,3.125,1.562,0.781$, and $0.391 \mu \mathrm{g} / \mathrm{ml}$. The test containing $3 \mathrm{ml}$ of Mueller-Hinton broth and $0.1 \mathrm{ml}$ bacterial suspensions (106 cells $/ \mathrm{ml}$ ) and $0.1 \mathrm{ml}$ algal extracts were incubated at $37^{\circ} \mathrm{C}$ for $24 \mathrm{hrs}$. The control tube without inoculum (negative control) is used for checking the sterility of the medium. Turbidity was measured at $650 \mathrm{~nm}$ to determine MIC against test pathogens. The MIC value was determined as the lowest concentration of the crude extract in broth medium that inhibited the visible growth of the test organism. For fungal isolates, instead of nutrient broth, Sabouraud dextrose broth was used and incubation condition was maintained at $28^{\circ} \mathrm{C}$ for $48 \mathrm{hrs}$ (yeasts) and $72 \mathrm{hrs}$ (molds) [26,27].

\section{Determination of antibacterial activity of Ulva species \\ Bacterial inoculum preparation}

Bacterial inoculum was prepared by inoculating a loopful of test organisms in $5 \mathrm{ml}$ of Nutrient broth and incubated at $37^{\circ} \mathrm{C}$ for $3-5 \mathrm{hrs}$ till a moderate turbidity was developed. The turbidity was matched with $0.5 \mathrm{McF}$ arland standards $\left(1.5 \times 10^{8} \mathrm{CFU} / \mathrm{ml}\right)$ and then used for the determination of antibacterial activity.

\section{Collection of test microorganisms}

About 20 different bacterial cultures and 10 fungal cultures used in this study were procured from GSL Medical College and Hospital, Rajamahendravaram. The Gram-positive organisms including Staphylococcus aureus, Streptococcus mutans, Bacillus subtilis, Streptococcus pyogenes, Bacillus cereus, Staphylococcus epidermidis, Enterococcus faecalis, and Corynebacterium diphtheriae were used as test organisms.

Gram-negative organisms such as Salmonella typhimurium, Serratia marcescens, Escherichia coli, Neisseria meningitidis, Klebsiella pneumoniae, Pseudomonas aeruginosa, Yersinia enterocolitica, and Shigella flexneri were used. Fungal organisms including Candida albicans, Aspergillus niger, Aspergillus fumigatus, Rhizopus oryzae, Mucor circinelloides, Penicillium marneffei, Syncephalastrum racemosum, and Absidia corymbifera were used as test organisms.

\section{Screening of antimicrobial activity assay of purified extracts}

The purified fractionated samples were screened for antibacterial activity by agar plate diffusion assay against human pathogens as discussed above. Streptomycin and nystatin were used as positive control and DMSO was used as the negative control.

\section{Well diffusion assay}

The antibacterial activity of the marine algal extracts was performed by agar well diffusion method (Kavangh, 1992). The nutrient agar medium prepared was inoculated with $18 \mathrm{hrs}$ old cultures of the above-mentioned test organisms and was transferred into sterile $15 \mathrm{~cm}$ diameter Petri dishes. The medium in the plates was allowed to set at room temperature for about 10 minutes and allowed to solidify in a refrigerator for about 30 minutes, 3 wells of $6 \mathrm{~mm}$ diameter were made in each plate at equal distance with a sterile cork borer. Stock solutions of the residual fractions were dissolved in 5\% DMSO and then in sterile water to reach a final concentration of $100 \mu \mathrm{g} / \mathrm{ml}$. Then, $100 \mu \mathrm{l}$ of the sample fractions were loaded aseptically into the respective wells of the plates with sterile micropipettes. In each plate, positive and negative controls were used. Antibiotic streptomycin $(100 \mu \mathrm{g} / \mathrm{ml})$ was used as positive control (standard), and DMSO was used as negative control. The plates were prepared and incubated for $24 \mathrm{hrs}$ at $37 \pm 1^{\circ} \mathrm{C}$ for bacteria. After incubation, the plates were examined for the formation of inhibition zone surrounding the well and diameter of the zone of inhibition was measured by using caliper; the experiment was repeated 3 times to get an average value and tabulated. The results having large inhibition zone diameter (IZD) with low MIC were considered, whereas small IZD with high MIC were omitted [29-31]. 
Triplicates of tests were carried out for each fraction against each of the test organism.

\section{Antimycotic assay}

Antifungal activity was performed using the same method as for bacteria. The test cultures of $C$. albicans and A. niger adjusted to turbidity of 0.5 McFarland standard were used as an inoculum. Instead of nutrient agar, Sabouraud dextrose agar was used. The inoculated medium was incubated at $25^{\circ} \mathrm{C}$ for 2 days for the fungal species. Nystatin $(100 \mu \mathrm{g} / \mathrm{ml})$ was used as positive control (standard) and DMSO used as negative control for antifungal studies. Triplicates of tests were carried out for each fraction against each of the test organism [29-31].

\section{Screening of the various functional groups by using FTIR}

All bonded atoms molecularly vibrate unless they are at various frequencies. Based on quantum mechanics, these frequencies correspond to the ground state (lowest frequency) of several excited states (higher frequencies). One way to cause the frequency of molecular vibration to increase is to excite the bond by making it to absorb light energy. For any given transition between two states, the light energy (determined by the wavelength) must exactly equal the difference in the energy between the two states (usually ground state $\left[E_{0}\right]$ and the first excited state $\left[E_{1}\right]$ ). The energy corresponding to this transition between molecular vibrational states is generally $1-10 \mathrm{kcal} / \mathrm{mole}$, which corresponds to the elements and type of bonds [21].

Difference in energy states $=$ Energy of light absorbed .

$$
\mathrm{E}_{0}-\mathrm{E}_{1}=\mathrm{hc} / \mathrm{l}
$$

Where, h=Planks constant, c=Speed of light, and l=The wavelength of light.

\section{Antioxidant activity: DPPH scavenging assay}

The free radical scavenging activity of the extracts and ascorbic acid as positive control was measured in terms of hydrogen donating or radical scavenging ability using the stable radical DPPH [31-33,36]. $2 \mathrm{~mL}$ of each algal sample and control at various concentrations $(600,500,400$, $300,200,100 \mu \mathrm{g} / \mathrm{mL}$ ) were added to $2 \mathrm{ml}$ of freshly prepared DPPH solution $(0.004 \%)$ in methanol.

The reaction was allowed for 30 minutes in dark and absorbance was measured at $517 \mathrm{~nm}$ using a spectrophotometer (Shimadzu UVVIS spectrophotometer). All experiments were repeated three times independently. The degree of decolorization of DPPH from purple to yellow indicated the scavenging efficiency of the algal sample. The percentage scavenging effect of DPPH was calculated using the following equation:

Percentage scavenging effect $=1-\left[\left(\mathrm{A}_{\text {sample }}-\mathrm{A}_{\text {sample blank }}\right) / \mathrm{A}_{\text {control }}\right] \times 100$

Where,

$A_{\text {sample }}=$ Absorbance of algal extract with DPPH in methanol,

$\mathrm{A}_{\text {sample blank }}=$ Absorbance of algal sample (sample/ascorbic acid),

$A_{\text {control }}=$ Absorbance of DPPH in methanol.

The $\%$ inhibition data were then plotted against log concentration fitted in a graph and half-maximal inhibitory concentration $\left(\mathrm{IC}_{50}\right)$ value was calculated by linear regression analysis.

\section{Statistical analysis}

All the experiments were performed in triplicates. Statistical differences between three extracts activities were determined using one-way ANOVA. Differences were considered statistically significant when $\mathrm{p}<0.05$.

\section{RESULTS AND DISCUSSION}

The findings of our present investigation demonstrates that marine algal extracts contain potential biological active compounds for development of anti-pathogenic agents in the pharmaceutical industries. The percentage yield for ethyl acetate, ethanol and aqueous extracts were found to be $27.90 \%, 24.38 \%$, and $17.5 \% \mathrm{w} / \mathrm{w}$. The phytochemical analysis of aqueous, ethanolic and ethyl acetate extracts of marine algae indicates the presence of the various phytochemical constituents such as alkaloids, aminoacids, flavanoids, carbohydrates, and sterols. Bioactive compounds of the isolates revealed the presence of sterols and amino acids by TLC. The summation of the nutritive value screening was total protein with $27.5 \pm 1.3 \%$, total crude fat with $0.5 \pm 0.1 \%$, total ash with $16 \pm 0.7 \%$, total carbohydrates with $43.2 \pm$ $1.5 \%$, and total moisture recorded $7.88 \pm 0.6 \%$. The extracts of ethyl acetate, ethanol and water showed MIC values of $3.125 \mu \mathrm{g} / \mathrm{ml}, 6.25$ $\mu \mathrm{g} / \mathrm{ml}$, and $12.25 \mu \mathrm{g} / \mathrm{ml}$ respectively for tested bacterial pathogens. In this preliminary antimicrobial screening, it revealed that ethyl acetate extracts showed antimicrobial effect against certain pathogenic strains and ethanolic extracts showed high antioxidant activity.

This research finding gives further scope to screen the chemical constituents of the extracts, which will be very useful to combat the various diseases caused by pathogenic microorganisms. The cultivable nature of marine flora is another advantage for development of potential antibacterial products.

\section{DISCUSSION}

Identification of the marine algae

Seaweeds collected were identified as Ulva species based on the morphological characteristics (Green algae: Chlorophyta) and verified

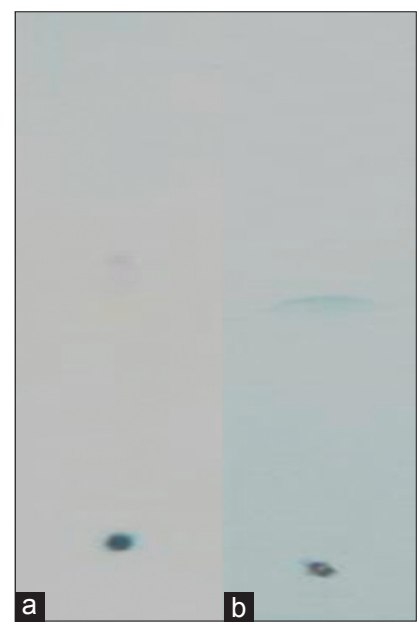

Fig. 2: Thin layer chromatography analysis of bioactive compounds from marine algae: (a) Sterols, (b) aminoacids

Table 1: Preliminary phytochemical tests of macroalgal extracts

\begin{tabular}{llll}
\hline Test & Aqueous & Ethanol & EtAc \\
\hline Alkaloids & + & + & ++ \\
Amino acids & + & ++ & ++ \\
Flavanoids & + & ++ & ++ \\
Glycosides & + & + & + \\
Tannins & - & - & - \\
Steroids & - & - & - \\
Terpenoids & + & + & + \\
Carbohydrates & + & + & ++ \\
Anthraquinones & - & - & - \\
Sterols & +++ & +++ & +++ \\
Saponins & + & + & + \\
\hline
\end{tabular}

+: Lower amounts, ++: Present in moderate amounts, +++: Present in higher amounts, -: Absent, EtAc: Ethyl acetate 
by Krishnamurthy Institute of Algology, Chennai. The percentage yield for EtAc, ethanol, and aqueous extracts was found to be $27.90 \%$, $24.38 \%$, and $17.5 \% \mathrm{w} / \mathrm{w}$, respectively. The highest yield of extractable substances was found in EtAc and ethanol, whereas the lowest yield was found with aqueous solvent. Phytochemical screening of aqueous, EtAc, and ethanol extracts exhibited different kinds of secondary metabolites such as alkaloids, aminoacids, flavanoids, carbohydrates, and sterols with the highest concentration, and trace amounts of glycosides, terpenoids and saponins were found in EtAc and ethanol as compared to aqueous extracts (Table 1 ).

\section{Bioactive compound analysis of macroalgae isolate}

The macroalgal bioactive compounds were separated by TLC. Bioactive compounds of the isolates revealed the presence of sterols and amino acids. The isolated bioactive compounds indicated the presence of antimicrobial activity. Bioactive compounds were recorded at the $\mathrm{R}_{f}$ values of 0.48 and 0.56 (Fig. 2).

\section{Nutritional value of collected marine algae}

Furthermore, in this study, nutritive value screening was carried out on the marine algae, obtained from the intertidal rocky surfaces of the Vishakhapatnam coastal area. The summation of the recorded information was total protein with $27.5 \pm 1.3 \%$, total crude fat with $0.5 \pm 0.1 \%$, total ash with $16 \pm 0.7 \%$, total carbohydrates with $43.2 \pm 1.5 \%$, and total moisture recorded $7.88 \pm 0.6 \%$ (Table 2).

\section{Antimicrobial activity}

The negative control (DMSO solvent) showed no zone of inhibition against all the pathogenic organisms. For the positive control (standard), the zone of inhibition was ranged between $28.1 \pm 0.4 \mathrm{~mm}$ and $16.5 \pm 0.3 \mathrm{~mm}$ for streptomycin sulfate $(100 \mu \mathrm{g} / \mathrm{ml})$ against the Grampositive and Gram-negative bacteria and $25.2 \pm 0.1 \mathrm{~mm}$ to $17.5 \pm 0.8 \mathrm{~mm}$ for nystatin $(100 \mu \mathrm{g} / \mathrm{ml})$ against the fungal pathogens.

\section{Antimicrobial activity of Ulva species}

To ascertain the MIC of the crude extracts showing antibacterial activity, various concentrations such as $100,50,25,12.5,6.25$, $0.625,3.125,1.562,0.781$, and $0.391 \mu \mathrm{g} / \mathrm{ml}$ were prepared and tested against the pathogenic organisms. The extracts of EtAc, ethanol, and water showed MIC values of 3.125, 6.25, and $12.25 \mu \mathrm{g} /$ $\mathrm{ml}$, respectively, for tested bacterial pathogens. The MIC values which were $<100 \mu \mathrm{g} / \mathrm{ml}$ for pure and individual compounds may be

Table 2: Nutritional value of Ulva species

\begin{tabular}{ll}
\hline Type of analysis (\% dry weight) & Ulva species \pm SD $^{*}$ \\
\hline Total protein (\% dry weight) & $27.5 \pm 1.3$ \\
Total crude fat (\% dry weight) & $0.5 \pm 0.1$ \\
Total ash (\% dry weight) & $16 \pm 0.7$ \\
Total carbohydrates (\% dry weight, by & $43.2 \pm 1.5$ \\
difference) & \\
Total moisture (\% fresh weight) & $7.88 \pm 0.6$ \\
\hline
\end{tabular}

${ }^{*}$ Each value is expressed as the mean $\pm S D(n=3)$. SD: Standard deviation suggestive of good antimicrobial activity. In addition, the inhibitory effect of fractions of microdilution method showed higher efficiency compared to the crude extracts.

The aqueous, ethanol, and EtAc crude extracts were then purified using column chromatography. Five to six fractions were further obtained after silica gel flash chromatography. They were eluted using a gradient polarity solvent (ethanol and EtAc). From the collected fractions, only two EtAc and ethanol fractions displayed a major spot in TLC using different dyes and UV light. The bioactive fractions of EtAc (F3 and F4) and ethanol (F2 and F3) were tested against all the selected pathogenic microorganisms and fraction F4 of EtAc and F3 of ethanol showed good activity against majority of the pathogenic organisms.

\section{Antimicrobial activity against Gram-positive bacteria}

The EtAc fractions (F4) showed highest mean zone of inhibition $(23.1 \pm 0.2 \mathrm{~mm}$ ) against the Gram-positive bacteria S. aureus (Fig. 3a) followed by $S$. mutans $(17.6 \pm 0.3 \mathrm{~mm})$, B. subtilis $(17.3 \pm 0.1 \mathrm{~mm})$, S. pyogenes $(13.8 \pm 0.1 \mathrm{~mm}), B$. cereus $(12.2 \pm 0.4 \mathrm{~mm})$, and S. epidermidis $(10.3 \pm 0.1 \mathrm{~mm})$. The test organisms $E$. faecalis and $C$. diphtheriae were highly resistant against EtAc fractions.

The ethanol fractions (F3) showed the highest mean zone of inhibition $(22.1 \pm 0.1 \mathrm{~mm})$ against the Gram-positive bacteria $S$. aureus followed by $B$. subtilis $(16.7 \pm 0.1 \mathrm{~mm}), S$. mutans $(15.1 \pm 0.3 \mathrm{~mm}), S$. pyogenes $(12.4 \pm 0.2 \mathrm{~mm}), \quad B$. cereus $(11.3 \pm 0.2 \mathrm{~mm})$, and $S$. epidermidis $(9.3 \pm 0.2 \mathrm{~mm})$. However, the organisms E. faecalis and C. diphtheriae were highly resistant against ethanol fractions as shown in Table 3.

\section{Antimicrobial activity against Gram-negative bacteria}

The EtAc fractions (F4) against Gram-negative bacteria, maximum zone of inhibition was recorded against $S$. typhimurium $(22.1 \pm 0.2 \mathrm{~mm})$ followed by $S$. marcescens $(21.5 \pm 0.1 \mathrm{~mm})$, E. coli $(20.2 \pm 0.4 \mathrm{~mm})$ shown in Fig. $3 \mathrm{~b}$ and Neisseria meningitis (16.4 $\pm 0.3 \mathrm{~mm})$. Ulva species showed lowest mean zone of inhibition $(12.5 \pm 0.1 \mathrm{~mm})$ against $K$. pneumoniae. The organisms P. aeruginosa (Fig. 3c), Y. enterocolitica, and S. flexneri showed high resistance against EtAc fractions.

The ethanol fractions (F3) against Gram-negative bacteria, maximum zone of inhibition were recorded against $S$. typhimurium $(17.3 \pm 0.1 \mathrm{~mm})$ followed by $S$. marcescens $(19.5 \pm 0.2 \mathrm{~mm})$, E. coli $(18.4 \pm 0.2 \mathrm{~mm})$, and N. meningitis $(15.3 \pm 0.2 \mathrm{~mm})$. Ulva species showed lowest mean zone of inhibition $(10.2 \pm 0.1 \mathrm{~mm})$ against $K$. pneumoniae. However, the organisms $P$. aeruginosa, $Y$. enterocolitica, and S. flexneri showed high resistance against ethanol fractions as shown in Table 4.

\section{Antimicrobial activity against unicellular and filamentous fungi} The EtAc fractions (F4) showed highest mean zone of inhibition $(23.1 \pm 0.1 \mathrm{~mm})$ against the pathogenic fungi $C$. albicans shown in Fig. $3 \mathrm{~d}$ followed by A. niger $(22.2 \pm 0.3 \mathrm{~mm})$, A. fumigatus $(20.5 \pm 0.4 \mathrm{~mm})$, $R$. oryzae $(20.3 \pm 0.2 \mathrm{~mm})$, and M. circinelloides $(14.5 \pm 0.3 \mathrm{~mm})$. Ulva species showed lowest mean zone of inhibition against $P$. marneffei $(10.4 \pm 0.1 \mathrm{~mm})$. Pathogenic fungi, S. racemosum, and A. corymbifera showed high resistance against EtAc fractions.

Table 3: Antimicrobial activity of bioactive fractions of macroalgae (Gram-positive)

\begin{tabular}{|c|c|c|c|c|c|c|}
\hline \multirow[t]{3}{*}{ Name of organism } & \multicolumn{6}{|c|}{ Zone of inhibition (mm) } \\
\hline & \multirow[t]{2}{*}{ Positive control $\pm \mathrm{SD}^{*}$} & \multirow[t]{2}{*}{ Aqueous extract $\pm S D^{*}$} & \multicolumn{2}{|c|}{ Ethanol extract $\pm S D^{*}$} & \multicolumn{2}{|c|}{ EtAc extract $\pm S D^{*}$} \\
\hline & & & F2 & F3 & F3 & F4 \\
\hline Bacillus subtilis & $26.3 \pm 0.3$ & $8.3 \pm 0.1$ & $15.6 \pm 0.2$ & $16.7 \pm 0.1$ & $16.5 \pm 0.2$ & $17.3 \pm 0.1$ \\
\hline Bacillus cereus & $27.5 \pm 0.1$ & $6.2 \pm 0.4$ & $10.5 \pm 0.3$ & $11.3 \pm 0.2$ & $11.5 \pm 0.3$ & $12.2 \pm 0.4$ \\
\hline Staphylococcus aureus & $28.1 \pm 0.4$ & $10.5 \pm 0.3$ & $21.3 \pm 0.2$ & $22.1 \pm 0.1$ & $22.3 \pm 0.1$ & $23.1 \pm 0.2$ \\
\hline Staphylococcus epidermidis & $28.4 \pm 0.2$ & $3.2 \pm 0.1$ & $7.8 \pm 0.4$ & $9.3 \pm 0.2$ & $9.5 \pm 0.3$ & $10.3 \pm 0.1$ \\
\hline Streptococcus pyogenes & $23.5 \pm 0.3$ & $5.5 \pm 0.2$ & $11.3 \pm 0.1$ & $12.4 \pm 0.2$ & $12.3 \pm 0.2$ & $13.8 \pm 0.1$ \\
\hline Streptococcus mutans & $22.7 \pm 0.7$ & $6.4 \pm 0.3$ & $14.2 \pm 0.2$ & $15.1 \pm 0.3$ & $15.5 \pm 0.1$ & $17.6 \pm 0.3$ \\
\hline Enterococcus faecalis & $20.3 \pm 0.3$ & NA & NA & NA & NA & NA \\
\hline Corynybacterium diptheriae & $16.5 \pm 0.7$ & NA & NA & NA & NA & NA \\
\hline
\end{tabular}

*Each value is expressed as the mean \pm SD $(n=3)$. SD: Standard deviation, NA: Not applicable 

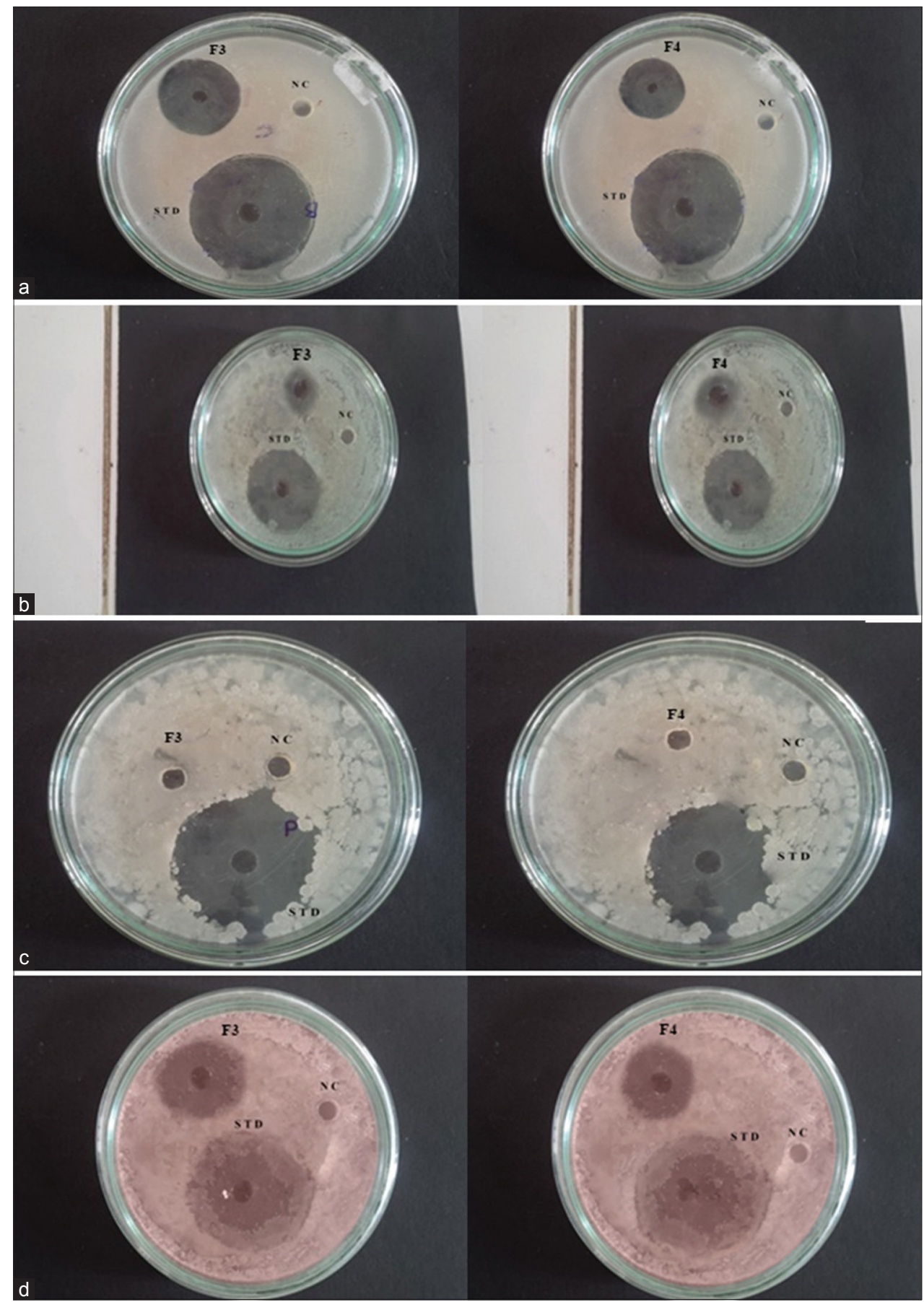

Fig. 3: Antibacterial and antifungal activities of ethyl acetate bioactive fractions, (a) bioactive fractions (F3, F4) of ethyl acetate against Staphylococcus aureus, (b) bioactive fractions (F3, F4) of ethyl acetate against Escherichia coli, (c) bioactive fractions (F3, F4) of ethyl acetate against Pseudomonas aeruginosa, (d) bioactive fractions (F3, F4) of ethyl acetate against Candida albicans. STD - Standards used for antibacterial and antifungal assay, NC - Negative control, F3, F4 - Bioactive fractions

The ethanol fractions (F3) showed highest mean zone of inhibition $(20.5 \pm 0.1 \mathrm{~mm})$ against the pathogenic fungi $C$. albicans followed by A. niger $(19.6 \pm 0.3 \mathrm{~mm}), A$. fumigatus $(18.5 \pm 0.2 \mathrm{~mm}), R$. oryzae $(18.2 \pm 0.4 \mathrm{~mm})$, and M. circinelloides $(13.5 \pm 0.2 \mathrm{~mm})$. Ulva species showed lowest mean zone of inhibition against $P$. marneffei $(9.8 \pm 0.3 \mathrm{~mm})$. Pathogenic fungi $S$. racemosum and A. corymbifera showed high resistance against ethanol fractions as shown in Table 5.

Moreover, in our study, the aqueous extracts exhibited minimum antimicrobial action against the tested pathogenic organisms. The EtAc and ethanolic extracts exhibited maximum zone of inhibition against Gram-positive organisms S. aureus, S. mutans, and B. subtilis; Gram-negative organisms such as S. typhimurium, S. marcescens, E. coli, and $N$. meningitis; fungal pathogens C. albicans, A. niger, A. fumigatus, R. oryzae, M. circinelloides and minimum activity for the other pathogens. The bioactive fractions exhibited no activity against E. faecalis, C. diphtheriae, P. aeruginosa, Y. enterocolitica, S. flexneri, S. racemosum, and $A$. corymbifera. In this study, the EtAc fractions showed higher antimicrobial activity than ethanolic and aqueous extracts.

As for the tests with pathogenic bacteria, the extracts showed differences in their activity. This variation in their antibacterial 
Table 4: Antimicrobial activity of bioactive fractions of macroalgae (Gram-negative)

\begin{tabular}{|c|c|c|c|c|c|c|}
\hline \multirow[t]{3}{*}{ Name of organism } & \multicolumn{6}{|l|}{ Zone of inhibition (mm) } \\
\hline & \multirow[t]{2}{*}{ Positive control $\pm \mathrm{SD}^{*}$} & \multirow[t]{2}{*}{ Aqueous extract $\pm S D^{*}$} & \multicolumn{2}{|c|}{ Ethanol extract $\pm S D^{*}$} & \multicolumn{2}{|c|}{ EtAc extract $\pm S D^{*}$} \\
\hline & & & F2 & F3 & F3 & F4 \\
\hline Pseudomonas aeruginosa & $17.5 \pm 0.2$ & NA & NA & NA & NA & NA \\
\hline Escherichia coli & $19.6 \pm 0.8$ & $8.2 \pm 0.2$ & $17.6 \pm 0.3$ & $18.4 \pm 0.2$ & $18.5 \pm 0.1$ & $20.2 \pm 0.4$ \\
\hline Salmonella typhimurium & $27.3 \pm 0.1$ & $10.5 \pm 0.3$ & $16.5 \pm 0.2$ & $17.3 \pm 0.1$ & $20.2 \pm 0.3$ & $22.1 \pm 0.2$ \\
\hline Klebsiella pneumoniae & $28.1 \pm 0.4$ & $5.2 \pm 0.1$ & $9.5 \pm 0.1$ & $10.2 \pm 0.1$ & $11.5 \pm 0.1$ & $12.5 \pm 0.1$ \\
\hline Neisseria meningitis & $18.3 \pm 0.1$ & $7.8 \pm 0.4$ & $14.6 \pm 0.4$ & $15.3 \pm 0.2$ & $14.7 \pm 0.6$ & $16.4 \pm 0.3$ \\
\hline Shigella flexneri & $23.1 \pm 0.2$ & NA & NA & NA & NA & NA \\
\hline Serratia marcescens & $19.6 \pm 0.1$ & $9.5 \pm 0.6$ & $13.2 \pm 0.3$ & $19.5 \pm 0.2$ & $19.6 \pm 0.2$ & $21.5 \pm 0.1$ \\
\hline Yersinia enterocolitica & $18.3 \pm 0.2$ & NA & NA & NA & NA & NA \\
\hline
\end{tabular}

*Each value is expressed as the mean \pm SD $(n=3)$. SD: Standard deviation, NA: Not applicable

Table 5: Antifungal activity of bioactive fractions of macroalgae

\begin{tabular}{|c|c|c|c|c|c|c|}
\hline \multirow[t]{3}{*}{ Name of organism } & \multicolumn{6}{|c|}{ Zone of inhibition (mm) } \\
\hline & \multirow[t]{2}{*}{ Positive control $\pm \mathrm{SD}^{*}$} & \multirow[t]{2}{*}{ Aqueous extract \pm SD* $^{*}$} & \multicolumn{2}{|c|}{ Ethanol extract $\pm S D^{*}$} & \multicolumn{2}{|c|}{ EtAc extract $\pm S D^{*}$} \\
\hline & & & F2 & F3 & F3 & F4 \\
\hline Candida albicans & $25.2 \pm 0.1$ & $11.5 \pm 0.3$ & $18.3 \pm 0.2$ & $20.5 \pm 0.1$ & $21.2 \pm 0.3$ & $23.1 \pm 0.1$ \\
\hline Aspergillus niger & $23.1 \pm 0.3$ & $10.3 \pm 0.2$ & $17.5 \pm 0.3$ & $19.6 \pm 0.3$ & $20.5 \pm 0.2$ & $22.2 \pm 0.3$ \\
\hline Aspergillus fumigatus & $22.3 \pm 0.2$ & $8.6 \pm 0.1$ & $16.3 \pm 0.4$ & $18.5 \pm 0.2$ & $19.3 \pm 0.4$ & $20.5 \pm 0.4$ \\
\hline Rhizopus oryzae & $18.4 \pm 0.4$ & $6.6 \pm 0.4$ & $16.6 \pm 0.1$ & $18.2 \pm 0.4$ & $19.4 \pm 0.1$ & $20.3 \pm 0.2$ \\
\hline Syncephalastrum racemosum & $19.6 \pm 0.4$ & NA & NA & NA & NA & NA \\
\hline Mucor circinelloides & $17.5 \pm 0.8$ & $7.3 \pm 0.2$ & $11.3 \pm 0.1$ & $13.5 \pm 0.2$ & $12.3 \pm 0.2$ & $14.5 \pm 0.3$ \\
\hline Absidia corymbifera & $19.3 \pm 0.6$ & NA & NA & NA & NA & NA \\
\hline
\end{tabular}

*Each value is expressed as the mean \pm SD $(n=3)$. SD: Standard deviation, NA: Not applicable

activities may be due to the method of extraction, extraction solvent used, the season at which samples were collected, the different bioactive substances and their concentrations present in the respective fraction [28]. These bacterial strains may have some kind of resistance mechanisms, e.g., enzymatic inactivation, target sites modification, and decrease intracellular drug accumulation or the concentration of the compound used may not be sufficient. The previous reports have shown that Gram-positive bacteria were effectively controlled by the marine algal extracts as compared to Gram-negative bacteria. The presence or absence of different chemical constituents in the purified fractions was responsible for different biological activities [29]. Many studies were reported on biological activities of algal extracts from different coastal regions around the world.

\section{Identification of functional groups by using FTIR}

FTIR spectrum of bioactive fractions showed strong bands at 3434.89, $2832.35,2732.66,2160.69,1594.45$, and $136.67 \mathrm{~cm}^{-1}$. The band at $3123.89 \mathrm{~cm}^{-1}$ showed $\mathrm{N}-\mathrm{H}$ stretching vibration. The position of $3687.75 \mathrm{~cm}^{-1}$ showed $\mathrm{O}-\mathrm{H}$ stretching vibration. FTIR spectra showed that $1594.87 \mathrm{~cm}^{-1}$ peak is identified as primary amide and N-H stretch vibration in the amide linkage of protein shown in Fig. 4.

\section{Antioxidant activity of Ulva species}

The stable DPPH radical model is a widely used, relatively quick and precise method for the evaluation of free radical scavenging activity. DPPH is a stable free radical and accepts an electron or hydrogen radical to become a stable diamagnetic molecule. Antioxidants on interaction with DPPH both transfer electron or hydrogen atom to DPPH and thus neutralizing its free radical character and convert it to DPPH and the degree of discoloration indicates the scavenging activity of the drug. The reduction capacity of DPPH radical is determined by the decrease in its absorbance at $517 \mathrm{~nm}$ induced by antioxidants. The decrease in absorbance of DPPH radical caused by antioxidants because of the reaction between antioxidant molecules and radical progress which results in the scavenging of the radical by hydrogen donation. It is visually noticeable as a change in color from purple to yellow.

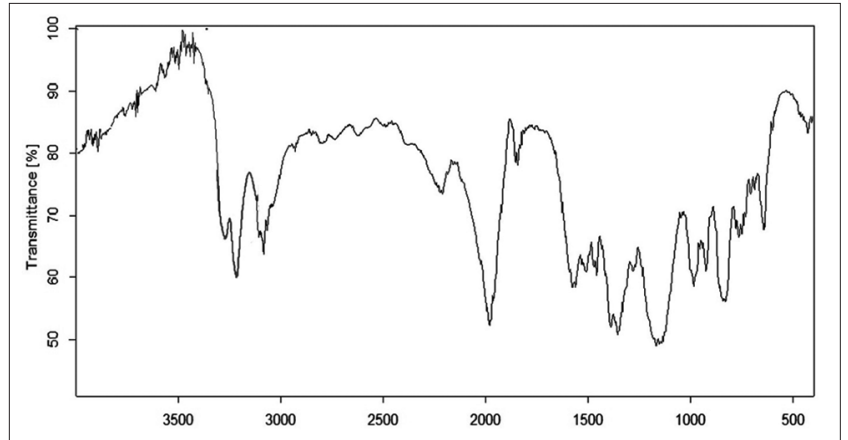

Fig. 4: Fourier transform infrared spectroscopy of isolated bioactive compounds from marine algae

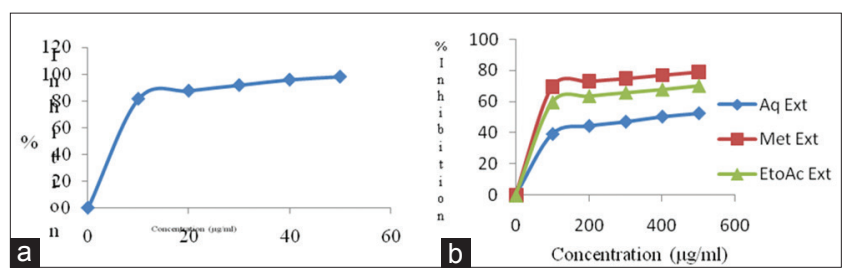

Fig. 5: 1,1-diphenyl-2-picrylhydrazyl radical scavenging activity of (a) ascorbic acid, (b) aqueous, ethanolic and ethyl acetate extracts of macroalgae

Hence, DPPH is usually used as a substance to evaluate the antioxidant activity [35]. Fig. 5a and b shows DPPH radical scavenging activity of standard ascorbic acid and Ulva extracts, respectively. The bioactive fractions of Ulva species showed highest DPPH scavenging activity as compared with ascorbic acid as standard IC s0 value is $0.632 \mathrm{mg} / \mathrm{ml}$. The $\mathrm{IC}_{50}$ values of green algal fractions were given in the following order: 
Ascorbic acid $(0.632 \mathrm{mg} / \mathrm{ml})>$ ethanol extract $(2.47 \mathrm{mg} / \mathrm{ml})>$ EtAc extract $(4.94 \mathrm{mg} / \mathrm{ml})$.

Recently, considerable research activity has been focused on marine algae for isolating and developing newer antimicrobial agents. During the past four decades, many novel bioactive compounds have been isolated from marine organisms. Since macroalgae show promising antimicrobial action, the present investigation is aimed to carry out antimicrobial activities from the separated fractions of marine algal crude extracts. The phytochemical analysis of aqueous, ethanolic and EtAc extracts of marine algae given in Table 1, which indicates the presence of the various phytochemical constituents such as alkaloids, aminoacids, flavanoids, carbohydrates, and sterols.

\section{CONCLUSIONS}

Finally, we conclude that algae of the Ulva species are a potential source for synthesis of novel natural medicines. It is important to taxonomically classify and standardize extractions, while identifying the active compounds to attenuate possible environmental interference that could undermine the pharmacochemical profile, and thus generate different pharmacologic effects. In addition, it is important to sensitize corporate researchers and financial agencies to support this cause. To research new drugs, it is necessary to evaluate other bioassay models to preserve the safety, efficacy and quality of the end products and there is a great need for toxicological, pharmacological, preclinical, and clinical studies.

In this preliminary biochemical screening, we can demonstrate that EtAc extracts showed antimicrobial effect against certain pathogenic bacterial and fungal strains and the ethanolic extracts exhibited the highest antioxidant activity. The coastal area of Visakhapatnam is bestowed with a large number of pharmaceutically useful marine algae, which could provide valuable secondary metabolites to control life-threatening diseases such as cancer, tumors, AIDS, and many human degenerative diseases. The study needs to be extended further to isolate, characterize, elucidate structure, and discover more bioactive metabolites from marine algae; which can be exploited for the production of lead molecules in pharmaceuticals. Economically, feasible standard operating procedures can be developed in preparing the extracts/fractions in large scale with reproducible antibacterial efficiency.

\section{REFERENCES}

1. Pereira RC, Costa-Lotufo LV. Bioprospecting for bioactives from seaweeds: Potential, obstacles and alternatives. Rev Bras Farmacogn 2012;22(4):894-905.

2. Msuya FE. The effect of stocking density on the performance of the seaweed Ulva reticulata as a biofilter in earthen pond channels, Zanzibar, Tanzania, Western Indian ocean. J Mar Sci 2007;6(1):65-72.

3. Silva M, Vieira L, Almeida AP, Kijjoa A. The marine macroalgae of the genus Ulva: Chemistry, biological activities and potential applications. J Oceanogr Mar Res 2013;1(1):1-6.

4. Stirk WA, Schwalb AN, Light ME, Medková J, Lenobel R, Strnad M, et al. Potential medicinal value of some South African seaweeds. South Afr J Bot 2003;69(4):462-8.

5. Christobel GJ, Lipton AP, Aishwarya MS, Sarika AR, Udayakumar A. Antibacterial activity of aqueous extract from selected macroalgae of Southwest coast of India. Seaweed Res Util 2011;33(1-2):67-75.

6. Chauhan J, Kasture A. Antimicrobial compounds of marine algae from Indian coast. Int J Curr Microbiol Appl Sci 2014;3(7):526-32.

7. Chakraborty K, Joseph D, Praveen K. Antioxidant activities and phenolic contents of three red seaweeds (division: Rhodophyta) harvested from the Gulf of Mannar of Peninsular India. J Food Sci Technol 2015;52(4):1924-35

8. Radhika D, Veerabahu C, Priya R, Mohaideen A. A comparative study of bio-potential of crude and fractionated extracts of some sea weeds from Tuticorin coast. Int J Phytopharmacol 2014;5(1):27-30.

9. Pramitha VS, Lipton AP. Antimicrobial effect of Ulva fasciata delile, 1813 solvent extracts against multidrug resistant human pathogenic bacteria and fish pathogens. Indian J Mar Sci 2014;43(9):1-9.

10. Moomeen HS, Padmavathy S. In vitro antagonistic activity of marine seaweed extracts against human pathogens. Unique J Pharm Biol Sci 2014;2(4):7-13.

11. Karthick P, Mohanraju R, Murthy KN, Ramesh CH. Antibacterial activity of seaweeds collected from South Andaman, India. J Algal Biomass Util 2015;6(1):33-6.

12. Desikachary TV. Cyanophyta. ICAR Monographs on Algae. New Delhi: ICAR; 1959. p. 686.

13. Anand NL, Radha RS, Hopper S, Ravati G, Subramianan TD. Perspectives in Phycology. New Delhi: Today and Tomorrow's Printers and Publishers; 1990. p. 383-91.

14. Prescott GW. Algae of the Western Great Lake Areas. Dubuque, Iowa: W.M.C. Brown Company Publisher; 1962.

15. Kavanagh F. Analytical Microbiology. Vol. II. New York, London: Academic Press; 1992. p. 241-3.

16. Bano A, Ayub Z. Antibacterial and antifungal activity in three species of Siphonaria (Gastropoda: Pulmonata) collected from rocky ledge of Mubarak village, Karachi. Pak J Zool 2012;44(6):1493-7.

17. Devi JA, Balan GS, Periyanayagam K. Pharmacognostical study and phytochemical evaluation of brown seaweed Sargassum wightii. J Coast Life Med 2013;1(3):199-204.

18. Seenivasan R, Rekha M, Indu H, Geetha S. Antibacterial activity and phytochemical analysis of selected seaweeds from Mandapam Coast, India. J Appl Pharm Sci 2012;2(10):159-69.

19. Abdel-Hamid MI, Belal SA, Azab YA, Abdel-Mogib M, Abdel-Aal EI. Nutritional value of some selected green microalgae. J Environ Sci 2015;44(3):455-67.

20. Ismail GA. Biochemical composition of some Egyptian seaweeds with potent nutritive and antioxidant properties. Food Sci Technol 2016;65:1-9.

21. Chandru S, Hephzibah AJ, Rajesh P, Kannan VR. Screening, evaluation of vibriocidal activity and characterization of bioactive substance from marine cyanobacteria. Afr J Microbiol Res 2013;7(17):1681-7.

22. Wagner H, Bladt S. Plant Drug Analysis, a Thin Layer Chromatography Atlas. $2^{\text {nd }}$ ed. Berlin: Springer; 2009. p. 306-64.

23. Widowati I, Lubac D, Puspita M, Bourgougnon N. Antibacterial and antioxidant properties of the red alga Gracilaria verrucosa from the North coast of Java, Semarang, Indonesia. Int J Latest Res Sci Technol 2014;3(3):179-85

24. Oumaskour K, Boujaber N, Etahiri S, Assobhei O. Anti-inflammatory and antimicrobial activities of twenty-three marine red algae from the coast of Sidi Bouzid (El Jadida-Morocco). Int J Pharm Pharm Sci 2013;5(3):145-9

25. Mhadhebi L, Chaieb K, Bouraoui A. Evaluation of antimicrobial activity of organic fractions of six marine algae from Tunisian Mediterranean coasts. Int J Pharm Pharm Sci 2012;4(1):534-7.

26. Mole MN, Sabale AB. Antibacterial activity of green seaweeds Chaetomorpha and Enteromorpha. Int $\mathrm{J}$ Pharm Bio Sci 2013;4(3):716-20

27. Omar HH, Shiekh HM, Gumgumjee NM, El-Kazan MM, El-Gendy AM. Antibacterial activity of extracts of marine algae from the red sea of Jeddah, Saudi Arabia. Afr J Biotechnol 2012;11(71):13576-85.

28. Etcherla M, Rao GM. In vitro study of antimicrobial activity in marine algae Caulerpa taxifolia and Caulerpa racemosa (C. Agardh). Int J Appl Biol Pharm Technol 2014;5(2):57-62.

29. Srivastava N, Saurav K, Mohanasrinivasan V, Kannabiran K, Singh M. Antibacterial potential of macroalgae collected from Madappam coast, India. Br J Pharmacol Toxicol 2010;1(2):72-6.

30. Akgul R, Suerdem TB, Akgul F. Antimicrobial activities of some marine algae and some Cyanobacteria from Canakkale (Turkey). J Algal Biomass Util 2013;4(3):35-40.

31. Kolsi RB, Frikha D, Jribi I, Hamza A, Feki L, Belghith K. Screening of antibacterial and antifongical activity in marine macroalgae and magnoliophytea from the coast of Tunisia. Int $\mathbf{J}$ Pharm Pharm Sci 2015;7(3):47-51

32. Saranya C, Parthiban C, Anantharaman P. Evaluation of antibacterial and antioxidant activities of seaweeds from Pondicherry coast. Adv Appl Sci Res 2014;5(4):82-90.

33. Sudha K, Priya KM, Kumari NV, Palanichamy V. Screening of antioxidant potential of green alga Codium adhaerens. Int J Drug Dev Res 2014;6(4):103-11.

34. Rhimou B, Hassane R, Nathalie B. Antioxidant activity of Rhodophyceae extracts from Atlantic and Mediterranean Coasts of Morocco. Afr J Plant Sci 2013;7(3):110-17.

35. Yildiz G, Dere E, Dere S. Comparison of the antioxidative components of some marine macroalgae from Turkey. Pak J Bot 2014;46(2):753-7.

36. Gouda S, Moharana RR, Das G, Patra JK. Free radical scavenging 
potential of extracts of Gracilaria verrucosa (L) (Harvey): An economically important seaweed from Chilika Lake, India. Int J Pharm Pharm Sci 2013;6(1):707-10.
37. Simić S, Kosanić M, Ranković B. Evaluation of in vitro antioxidant and antimicrobial activities of green microalgae Trentepohlia umbrina. Notulae Bot Horti Agrobot 2012;40(2):86-91 